\title{
Foreign Body Aspiration in the Left Bronchial Tree: Apropos of Two Cases
}

\author{
Joana Lages ${ }^{\mathrm{a}, \mathrm{c}}$, Cristina Angela ${ }^{\mathrm{b}}$, Rui Rolo ${ }^{\mathrm{a}}$
}

\begin{abstract}
Foreign body aspiration (FBA) is a potentially life-threatening event. The most common site of aspiration is the right main bronchus. We present the cases of two patients with a history of intravenous drug abuse, both with foreign bodies logded in the left upper lobar bronchus (ULB) probabily aspirated during a period of unconsciousness, immediately after drug injection. We believe that the position in which individuals were injected was possibly related to the location of the object.
\end{abstract}

Keywords: Foreign body; Aspiration; Adult; Bronchoscopy; Needle

\section{Introduction}

Foreign body aspiration (FBA) is a potentially life-threatening event. It is more common in children and has a lower rate in adults [1-6]. Risk factors in adults include loss of consciousness due to trauma, drug or alcohol intoxication, or anesthesia [7]. The most common site of aspiration is the right main bronchus. FBA in adults usually has a subtle presentation with a paucity of image findings, being crucial a high grade of clinical suspicion. Direct visualization of the foreign body by bronchoscopy is required for definitive diagnosis and treatment [8].

\section{Case Reports}

We present the cases of two patients with a history of intravenous drug abuse, both with foreign body logded in the left upper lobar bronchus (ULB).

In the first case, the patient was a 32-year-old male, a former intravenous drug user with a history of intravenous

Manuscript submitted February 24, 2018, accepted March 15, 2018

aDepartment of Respiratory Medicine, Hospital de Braga, Braga, Portugal bepartment of Internal Medicine, Hospital de Braga, Braga, Portugal ${ }^{\mathrm{c} C o r r e s p o n d i n g ~ A u t h o r: ~ J o a n a ~ L a g e s, ~ D e p a r t m e n t ~ o f ~ R e s p i r a t o r y ~ M e d i c i n e, ~}$ Hospital de Braga, Sete Fontes, Sao Victor, 4710-243 Braga, Portugal.

Email: joana.vale.lages@gmail.com

doi: https://doi.org/10.14740/jmc3025w consumption. Patient had a history of human immunodeficiency virus (HIV) infection in acquired immunodeficiency syndrome (AIDS) stage and hepatitis $\mathrm{C}$ virus (HCV) infection. He was admitted for anorexia, prostration and fever with 1-month evolution. He reported having chronic cough. There were no other lung-related symptoms relevant for this case. Physical examination showed no relevant changes. Chest radiograph presented left reticular infiltrate and chest computed tomography (CT) revealed the presence of an endoluminal image, in left ULB, favoring the presence of a foreign body (Fig. 1a). Bronchoscopy revealed the presence of an intravenous injection needle in the region of ULB, with granulation tissue around it (Fig. 1b). The object was removed by rigid bronchoscopy (Fig. 1c).

In the second case, the patient was a 47-year-old male, a former intravenous drug user with a history of intravenous consumption. Patient had HIV infection in AIDS stage and $\mathrm{HCV}$ infection. He was admitted for study of cough with hemoptoic sputum with 2 months of evolution and associated pleuritic pain and weight loss. Physical examination showed no relevant changes. Chest radiograph presented no significant alterations. Chest CT showed a foreign body in the main bronchus and left ULB (Fig. 1d). Bronchoscopy revealed a foreign body (intravenous injection needle) located in the ULB (Fig. 1e). Removal by rigid bronchoscopy was performed.

\section{Discussion}

After reviewing the history, we assume that the needles may have been aspirated during a period of unconsciousness, immediately after drug injection. Since the location of foreign body is often the right bronchial tree and, in both cases, the otherwise was found, led us to conclude that the position in which individuals were injected was possibly related to the location of the object. Both patients preferentially used the left arm venous circulatory system for administration, bended to the left side and holding the needle with their mouth while applying the tourniquet on the arm, leaving the left bronchial tree more exposed during FBA.

The explanatory two clinical cases with FBA resulting in the same location, the same history of drug addiction and the same technique of administration of drugs, aim to highlight a possible explanation for the atypical location of the foreign body and draw attention to a subtle clinical and imaging presentation, and therefore the crucial high grade of clinical suspi- 

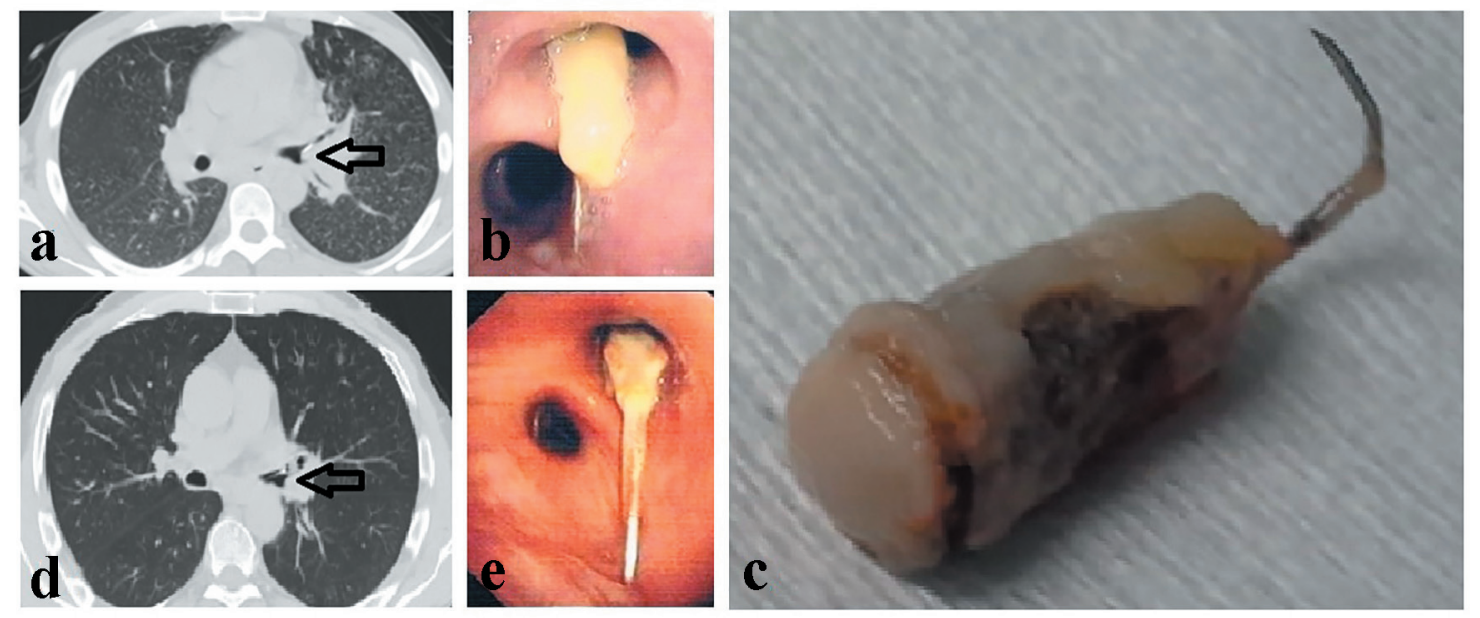

Figure 1. (a) Chest computed tomography (CT) showing an endoluminal image (arrow) in left upper lobar bronchus (ULB). (b) Bronchoscopy showing an intravenous injection needle in the region of left ULB. (c) Intravenous injection needle after removal. (d) Chest CT showing a foreign body (arrow) in the main bronchus and left ULB. (e) Bronchoscopy showing an intravenous injection needle located in the left ULB.

cion is needed.

\section{Grant Support}

None.

\section{Conflict of interest}

The authors have no conflict of interest to declare.

\section{References}

1. McGuirt WF, Holmes KD, Feehs R, Browne JD. Tracheobronchial foreign bodies. Laryngoscope. 1988;98(6 Pt 1):615-618.

2. Rafanan AL, Mehta AC. Adult airway foreign body removal. What's new? Clin Chest Med. 2001;22(2):319-330.
3. Limper AH, Prakash UB. Tracheobronchial foreign bodies in adults. Ann Intern Med. 1990;112(8):604-609.

4. Lan RS. Non-asphyxiating tracheobronchial foreign bodies in adults. Eur Respir J. 1994;7(3):510-514.

5. Chen CH, Lai CL, Tsai TT, Lee YC, Perng RP. Foreign body aspiration into the lower airway in Chinese adults. Chest. 1997;112(1):129-133.

6. Casalini AG, Majori M, Anghinolfi M, Burlone E, D'Ippolito R, Toschi M, Pisi G, et al. Foreign body aspiration in adults and in children: advantages and consequences of a dedicated protocol in our 30-year experience. J Bronchology Interv Pulmonol. 2013;20(4):313-321.

7. Boyd M, Chatterjee A, Chiles C, Chin R, Jr. Tracheobronchial foreign body aspiration in adults. South Med J. 2009;102(2):171-174.

8. Sehgal IS, Dhooria S, Ram B, Singh N, Aggarwal AN, Gupta D, Behera D, et al. Foreign body inhalation in the adult population: experience of 25,998 bronchoscopies and systematic review of the literature. Respir Care. 2015;60(10):1438-1448. 